\title{
PHYTOCHEMICAL SCREENING, BIOLOGICAL STUDIES AND GC-MS ANALYSIS OF EXTRACT OF BIDEN PILOSA L
}

Khanal DP ${ }^{1 \dagger}$, Rana $\mathrm{R}^{1}$, Raut $\mathrm{B}^{1}$ and Dhakal RP ${ }^{2}$

${ }^{1}$ Manmohan Memorial Institute of Health Sciences, Soalteemode, Kathmandu, Nepal.

${ }^{2} \mathrm{M}$ Sc, PhD, Nepal Academy of Science and technology, National Forensic Science Laboratory, Khumaltar, Lalitpur, Nepal.

${ }^{\dagger}$ Corresponding author: Dr. Dharma P Khanal PhD, Email: drdpk@mmihs.edu.np

\section{ABSTARCT}

Objective: The aim of the research work was to carry out the extraction of areal parts of Biden pilosa $L$ by hydroalcholic and Hexane, ethyl acetate and acetone mixture followed by qualitative phytochemical analysis, acute oral toxicity test, anti-inflammatory test and GC-MS analysis of the extracts.

Method: The hydro-alcoholic and HEA(n-hexane, ethyl acetate and acetone) extraction was done from aerial parts using ethanol and water in the ratio 70:30 and n-hexane, ethyl acetate and acetone in the ratio of 1:1:1 (HEA extract) respectively. Acute oral toxicity test was performed OECD guidelines. The single spot in TLC was obtained using n-hexane as solvent for HEA fraction and finally phytocomponents were identified by GC-MS present in that spot. In vitro anti-inflammatory activity was performed by human RBC membrane stabilization method.

Result: The phytochemical test results obtained indicate that hydro-alcoholic extract of aerial part of Bidens pilosa L. possess alkaloids, tannins, terpenoids and saponins whereas HEA extract possess alkaloids, flavonoids, tannins. Both hydro-alcoholic and HEA extracts were found to be safe up to the dose of $2000 \mathrm{mg} / \mathrm{kg}$ BW of the mice. Both extracts showed significant in vitro antiinflammatory activity in a concentration dependent manner. The GC-MS analysis of HEA extract of aerial parts showed the presence of the sixteen different compounds from partially separated extract from TLC plates.

Conclusion: Hydro-alcoholic extract of aerial part of Bidens pilosa L. possess alkaloids, tannins, terpenoids and saponins whereas HEA extract possess alkaloids, flavonoids, tannins. Both hydroalcoholic and HEA extracts were found to be safe up to the dose of $2000 \mathrm{mg} / \mathrm{kg}$ BW of the mice. 
The GC-MS analysis of HEA extract of aerial parts showed the presence of the sixteen different compounds.

Keywords: Bidens pilosa L, Extract, phytochemicals, biological activity, GC-MS analysis.

\section{INTRODUCTION}

Herbal drugs from natural sources like plants are in used since the traditional system of medicines; they represent a precious reservoir of innovative bioactive molecules ${ }^{1}$. Throughout the ages humans have relied on nature for their basic needs for the production of foodstuffs, shelters, clothing, means of transportation, fertilizers, flavors and fragrances, and not least, medicines. Plants have formed the basis of sophisticated traditional medicine systems that have been in existence for thousands of years. Herbal drugs from natural sources like plants are used all around the world ${ }^{2}$.

Bidens pilosa L. (Asteraceae) commonly known as 'Spanish needle' has respectable place in traditional literature because of its different uses. Bidens pilosa L. is originally native to South America. It is known by Kaalo kuro in Nepali and Beggar's ticks, Blackjack, Cobbler's pegs, Devil's needles, farmer's friend, Burmarigold in English. The genus contains about 280 species. It is an annual herb with branching habitat to about $1.8 \mathrm{~m}$ high, flowering plant having white petals around an intense bunch of orange florets, capable of invading vast range of habitats ranging from moist soil, sand, limerock, or dry, infertile soil and low to high altitudes of up to 3600m. It is widely distributed all over the world, particularly in tropical and sub-tropical regions ${ }^{3}$. GC-MS is an analytical method that combines the feature of gas chromatography and mass spectrometry to identify different phytocomponents of the plant extracts. Identification of structural features of even tiny compounds of the extract is done here. GC-MS identify the molecular mass, molecular formula, percentage peak area, retention time and structural features of the isolated compounds of the extract. GC-MS facilitates the identification and robust quantification of the isolated fraction ${ }^{4}$. Almost 200 compounds have been isolated from B. pilosa L, specially flavonoids and polyacetylenes. Other chemical constituents like polyacetylenic glycosides, aurons, auron glycosides, p-coumeric acid derivatives, caffeoylquinic acid derivatives, hydroxycinnamic acid pheophytins, diterpenes, tannins, phytosterols, ascorbic acid, carotene, essential oils, saponins, steroids and flavonoids and many others were recognized in this plant. And it has been reported to 
possess the pharmacological properties like antibacterial, anti-inflammatory and anti-allergic, antimalarial, anti-hyperglycemic, anti-hypertensive, antiulcerogenic, hepatoprotective, antileukemic, anticancer, antipyretic, anti-virus, anti-angiogenic, anti-rheumatic, $\mathrm{T}$ helper cell modulator, immunosuppressive activity ${ }^{1}$.

In different areas of Nepal the plant juice is applied to cure fresh cuts and wounds, leaf juice is used to check bleeding, inflammation and used as a mouth wash to relieve toothache ${ }^{3,5}$. In South Africa, leaf decoction is used to treat headache, ear infection, kidney problems and flatulence reduction. The leaf extract is used to cure malaria, stomach and mouth ulcers, diarrhoea, hangover and whole plant is taken as antidote 6 . It is used in traditional medicines for inflammation and the treatment of various diseases, including hepatitis and diabetes ${ }^{7}$.

Khemraj et al ${ }^{8}$. Concluded that Bidens pilosa $L$ has large range of pharmacological activity due to presence of diverse class of chemical constituents like polyacetylenes, aurons, flavonoids, chalcons and their glycosides ${ }^{1}$. The study conducted by Khanh et al. found that application of it significantly suppressed the growth of weed by $80 \%$ than hand-weeding and herbicide treatments and enhanced the rice yields by $20 \%$. Total 23 phenolic compounds including salicylic acid, vanillin, p-hydroxybenzoic acid, p- caumaric acid, ferulic acid, polyacetylenes and triterpenes were identified and isolated. Caffeic acid was in highest amount followed by pyrocatechin ${ }^{3}$.

Jianguo Wu et al ${ }^{9}$. Investigate the ethanolic extracts from Bidens pilosa L. for Antioxidant Activities and Cytotoxicity against Human Tumor Cells, and found that the IC50 value 43.53 $\mu \mathrm{g} / \mathrm{ml}$. The result suggested that it has potent cytotoxic effect.

Bartolome et al., in his study described about the botanical properties, traditional uses, phytochemistry and pharmacology of the plant Bidens pilosa L. The plant is used as a herbal and as an ingredient in tea or herbal medicines. Till today, total of 201 compounds comprising of 70 aliphatics, 60 flavonoids, 25 terpenoids, 19 phenylpropanoids, 13 aromatics, 8 porphyrins and other 6 compounds have been identified. Plant is traditionally used to treat wide variety of ailments. Scientific studies demonstrated that Bidens pilosa $L$ extract have antitumor, anti-inflammatory, antidiabetic, antihyperglycemic, antioxidant, immunomodulatory, antimalarial, antibacterial, antifungal, antihypertensive, vasodilatory and anti-ulcerative activities ${ }^{10}$. 


\section{Original Article}

Singh et al. reported the , GC-MS analysis of methanol extract of Bidenspilosa L. showed presence of six compounds including 3,7,11,15-Tetramethyl-2-Hexadecen-1-ol (57.82\%), 9H-fluorene-9diazo (18.14\%), 1-Octadecyne (6.92\%), N-Hexadecenoic acid (6.70\%), 1H,3AMethanozulene,Octahydro-1,4,9,9-tetramethyl (6.46\%), 1,3,6,10-Dodecatetraene,3,7,11-trimethy $\mathrm{l}(3.96 \%)^{11}$.

\section{MATERIALS AND METHOD}

Collection of plant material: The aerial parts of the Bidens pilosa L. were collected solely from Kirtipur area of Kathmandu, Nepal.

\section{Processing of plant}

Drying: The aerial parts of Bidens pilosa L.were shade dried for one month.

Size Reduction: After complete drying, the samples were cut into small pieces and grinded with the electric grinder to obtain coarse powder.

\section{Chemicals and equipment}

Chemicals: All the solvents and chemicals used during the experimental process such as extraction, phytochemical screening, toxicological, anti-inflammatory, study and chromatographic separation were of analytical grade purchase from local market. Solvents like n-hexane, acetone, ethyl acetate, ethanol, distilled water, DMSO (dimethyl sulfoxide), tween 80 while chemicals such as, Sodium acetate monohydrate, ascorbic acid, sodium chloride, citric acid, dextrose, sodium citrate, ferrous sulphate, sodium hydroxide, Diclofenac sodium, chloroform, glacial acetic acid, $\mathrm{HCl}$, ferric chloride, zinc turnings, Dragendroff's reagent, Mayer's reagent, Fehling solution A and B, silica gel etc. were used.

Equipment and glass wares: The following equipment and glass wares were used: Electric Grinder (Panasonic, Japan) ,Electric balance (Ohaus, China), Rotary evaporator (Accumax, India), Hot air Oven (Memmate, Germany), Autoclave (Accumax, India), Hot air Oven (Memmate, Germany), UV-Visible Spectrophotometer (Thermo Spectronics), GC-MS (Shimadzu GC-MS 2010 Ultra) and all glasswares of Borosil, India were used.

\section{Extraction of plant materials by hexane, ethyl acetate and acetone}

For this fraction, $50 \mathrm{gm}$ of powder of aerial parts of B. pilosa was taken and soaked into $166 \mathrm{ml}$ each of n-hexane, ethyl acetate and acetone (1:1:1). It was frequently shaken for $0,4,6,12,24,30$ 


\section{Original Article}

and 48hours. Finally, solution were filtered first through muslin cloth and then through whattman filter paper No. 1, and the filtrates were concentrated using rotary evaporator at $45^{\circ} \mathrm{C}$ under vacuum for solvent removal and resultant mass was used for further experiments.

\section{Extraction of plant materials by hydro-alcoholic fraction}

For this fraction, $50 \mathrm{gm}$ of powder of aerial parts of B. pilosa was taken and soaked into $500 \mathrm{ml}$ mixture of ethanol and water, i.e. $350 \mathrm{ml}$ ethanol and $150 \mathrm{ml}$ water(70:30).For 0,4,6,12,24,30 and 48 hours, the mixture was frequently shaken. Finally, the solution were filtered first through muslin cloth and then through whattman filter paper No.1, and the filtrates were concentrated using rotary evaporator at $45^{\circ} \mathrm{C}$ under vacuum for solvent removal and resultant mass was used for further experiments.

\section{Phytochemical screening:}

The following reagents were used: Mayer's Test, Dragendroff's Test, Molisch's Test, Salkowski's Test, Shinoda Test, Alkaline Reagent Test and Zinc Hydrochloride Test (Detail is given in Annex1).

\section{Acute oral toxicity}

Acute oral toxicity test of both the extracts were performed in Natural Product Research Laboratory, Thapathali, Kathmandu, Nepal as per protocol (as per OECD) provided by Natural Products Research Laboratory.

\section{Anti-inflammatory activity (HRBC membrane stabilization technique)}

Preparation of Blood samples for Membrane Stabilization Assay: The blood was collected from the healthy volunteer who had not taken any NSAIDS prior to 2 week of experiment and mixed with equal volume of Alsever solution (2 \% dextrose, 0.8\% sodium citrate, $0.05 \%$ citric acid and $0.42 \% \mathrm{NaCl})$. 


\section{Original Article}

Preparation of standard solution: Diclofenac sodium was used as standard and solution of concentrations of $500 \mu \mathrm{g} / \mathrm{ml}$ was prepared with distilled water. To this solution $1 \mathrm{ml}$ phosphate buffer (0.15 M, pH 7.4), $2 \mathrm{ml}$ of hypo-saline (0.36\%) and $0.5 \mathrm{ml}$ Of HRBC suspension was added, incubated at $30^{\circ} \mathrm{C}$ for $30 \mathrm{~min}$, centrifuge at $3000 \mathrm{rpm}$ for $20 \mathrm{~min}$ and absorbance was measured at $560 \mathrm{~nm}$.

It was then centrifuged at 3000 rpm for 5 min and supernatant was removed. The cell suspension was washed with isosaline (0.85\%, $\mathrm{pH} 7.2)$ and suspension was made with isosaline $(10 \% \mathrm{v} / \mathrm{v})$. Preparation of test sample: $1 \mathrm{ml}$ of test samples of different concentration ( 500 and $1000 \mu \mathrm{g} / \mathrm{ml}$ ), $1 \mathrm{ml}$ of phosphate buffer (0.15 M, PH 7.4), $2 \mathrm{ml}$ of hypo-saline (0.36 \%) and $0.5 \mathrm{ml}$ of HRBC suspension were added, incubated at $37^{\circ} \mathrm{C}$ for $30 \mathrm{~min}$ and centrifuge at $3000 \mathrm{rpm}$ for $20 \mathrm{~min}$ and the absorbance was measured by spectrophotometer at $560 \mathrm{~nm}$.

Preparation of control solution: In control solution instead of hypo-saline solution distilled water was added, $0.5 \mathrm{ml}$ of HRBC suspension, $1 \mathrm{ml}$ of phosphate buffer.

Data analysis: The percentage of hemolysis and membrane stabilization or protection was calculated by using the formula:

Percentage prevention of lysis $=100-\frac{O D \text { of sample }}{\text { OD of control }} \times 100 \%$ 


\section{Original Article}

\section{Chromatographic separation of non-polar extract of Bidens pilosa L.}

Preparation of TLC plate: TLC plates $20 \times 20$ were prepared by using standard TLC kit. The resulted plates were dried and activated by heating in an oven for one hour at $110^{\circ} \mathrm{C}$ and cooled at room temperature before use. The HEA extract was separated by applying with capillaries.

\section{GC-MS analysis of the yellow tailing spot}

The TLC plates with the tailing spots was scrapped and dissolved in about $5 \mathrm{ml} n$-hexane. It was then filtered through whattman filter paper No.1, the solution was evaporated to dryness and sent for GC-MS analysis to National Forensic Science Laboratory, Khumaltar, Lalitpur.

\section{RESULTS AND DISCUSSION}

\section{Phytochemical screening}

The hydro-alcoholic extract of aerial part of Bidens pilosa $L$ contains alkaloid, tannin, terpenoids and saponins whereas HEA extract possess alkaloid, flavonoid, and tannin. The leaves extract $B$. pilosa L from southwest Kenya was found to have glycoside, alkaloid, saponins, tannin, steroid and flavonoid. The difference may be due to the geographical variation ${ }^{11}$. (Detail in Annex-1 and 2).

An acute oral toxicity, the extract was found to be non-toxic up to 2000mg/kg dose, hence LD50 value for both extract was $>2000 \mathrm{mg} / \mathrm{kg}$ body weight. (Detail is presented in Table No. 2 in Annex3).

In vitro evaluation of anti-inflammatory properties by HRBC membrane stabilization method, antiinflammatory activity of polar extract at $500 \mu \mathrm{g} / \mathrm{ml}$ and $1000 \mu \mathrm{g} / \mathrm{ml}$ was found to be $34.18 \%$ and 49.68\%, and of non-polar extract 42.03 and 55.41\% respectively. The result indicated that the both extracts at various concentrations has significant anti-inflammatory property. Details in Annex-4, Table-2). 


\section{Original Article}

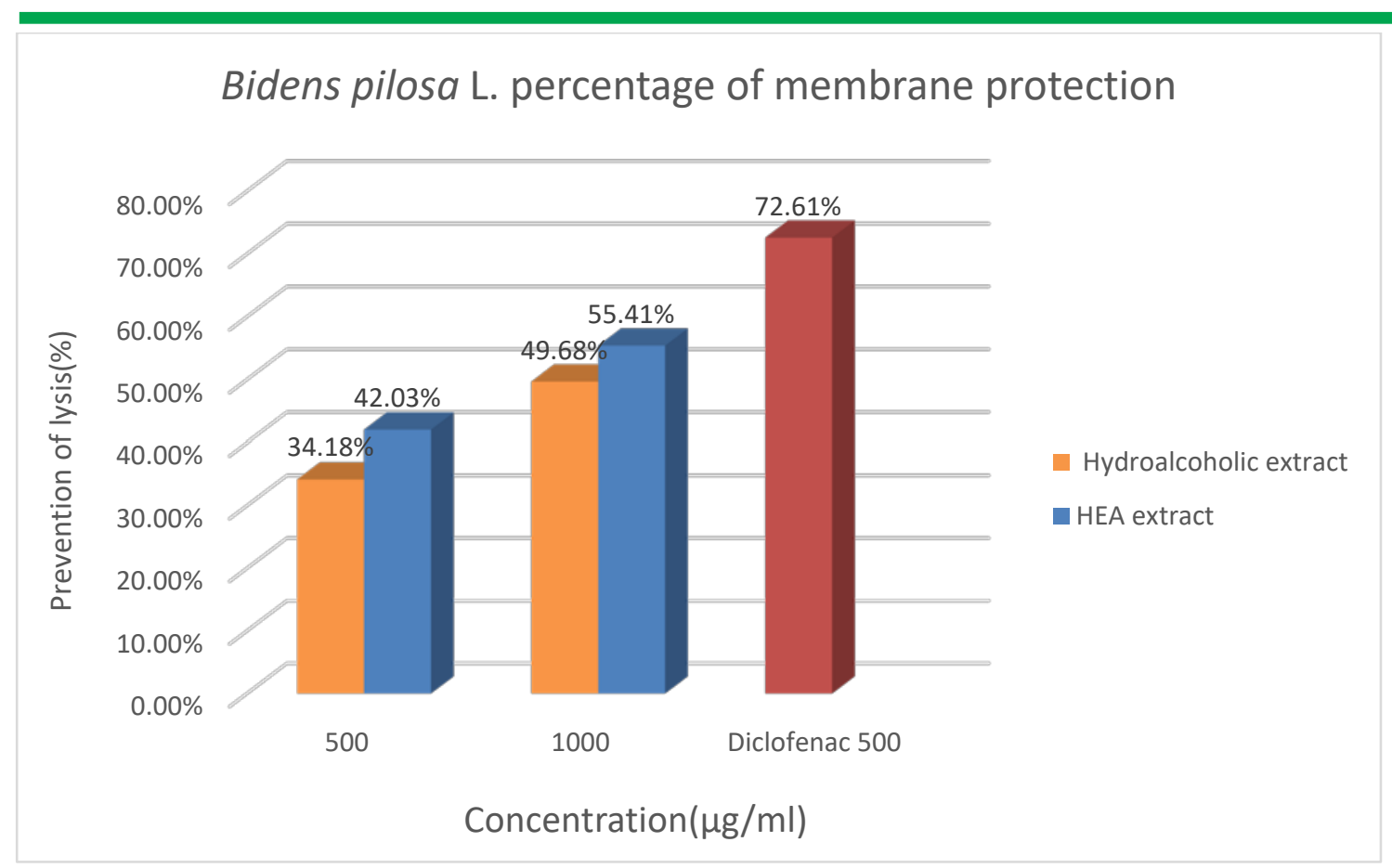

Fig2: In-vitro Anti-inflammatory property of extract of Biden pilosa L. and Diclofenac

\section{GC-MS analysis}

The results pertaining to GC-MS analysis led to identification of sixteen compounds from the GC fractionations of the non-polar(n-hexane, acetone and ethyl acetate) extract of Bidens pilosa L.(Detail are presented in Table No. 2 in Annex-5).

The constituents and their calculated percentage peak area composition include 9H-fluorene-9diazo (11.66\%), Eicosane, 7-hexyl-(11.35\%), Eicosane, 10-methyl (11.21\%), Nonadecane, 2methyl (8.06\%), 11-Octadecenoic acid, methyl ester(4.80\%), 4,8,12-Tetradecatrienal,5,9,13trimethyl (2.95\%), Pentadecanoic acid, 14-methyl, methyl ester (1.99\%), 1-Iodo-2methylundecane (1.32\%), Hexadecenoic acid, 2,3-dihydroxypropyl ester (0.82\%), 2-Methyl-Z,Z3,13-octadecadienol (0.78\%), Eicosane, 2-methyl (0.74\%), Hexadecenoic acid, 15-methyl, methyl ester (0.65\%), cis-alpha-Bisabolene (0.59\%), Eicosane, 3-methyl (0.51\%), Docosane, 2,21dimethyl (0.36\%), Pentaerythritol, bis-O-(9-borabicyclo[3.3.3]non-9-yl)-di-O-methyl (0.21\%). 


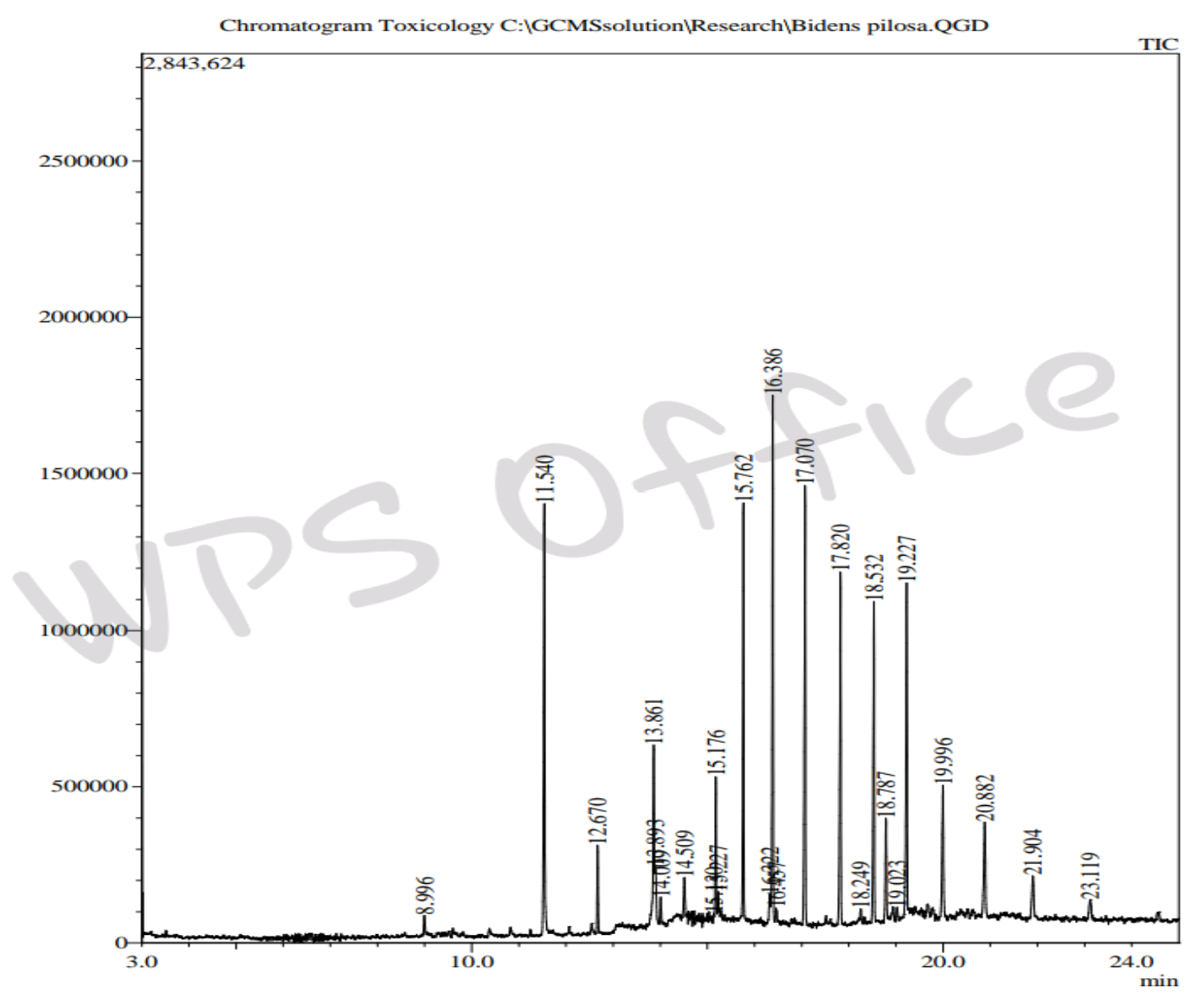

Fig.4: GC-MS Chromatogram of HEA extract of Bidens pilosa L.

Biological activity of Phytocomponents Identified in the HEA extracts of Bidens pilosa L. Singh et.al $^{11}$, mentioned that GC-MS analysis of methanol extract of Bidens pilosa L. showed presence of six compounds including 3,7,11,15-Tetramethyl-2-Hexadecen-1-ol (57.82\%), 9H-fluorene-9diazo (18.14\%),1-Octadecyne (6.92\%), N-Hexadecenoic acid (6.70\%), 1H,3A-Methanozulene, Octahydro-1,4,9,9-tetramethyl (6.46\%), 1,3,6,10-Dodecatetraene,3,7,11-trimethyl （3.96\%) [20=14]. Difference in results from previous study might be due to differences in time of plant collection, method of extraction, geographical variation which can significantly affect the accumulation of the chemical constituents in the plant material. 


\section{CONCLUSSION}

Phytochemical screening shows the presence of alkaloids, tannins, terpenoids, saponins, flavonoids in the extracts of Bidens pilosa L. The acute oral toxicity test of hydro-alcoholic and HEA extracts of Bidens pilosa L. suggests, the both extracts are safe for the use up to $2000 \mathrm{mg} / \mathrm{kg}$ body weight. At concentration of $500 \mu \mathrm{g} / \mathrm{ml}$ and $1000 \mu \mathrm{g} / \mathrm{ml}$, the hydroalcoholic extract inhibited $34.18 \%$ and $49.68 \%$ RBC hemolysis respectively. And at concentration of $500 \mu \mathrm{g} / \mathrm{ml}$ and 1000 $\mathrm{\mu g} / \mathrm{ml}$ HEA extract prevent $42.03 \%$ and 55.41\% hypo tonicity.

The constituents and their calculated percentage peak area composition include 9H-fluorene-9diazo(11.66\%), Eicosane, 7-hexyl-(11.35\%), Eicosane, 10-methyl(11.21\%), Nonadecane, 2methyl(8.06\%), 11-Octadecenoic acid, methyl ester(4.80\%), 4,8,12-Tetradecatrienal,5,9,13trimethyl(2.95\%), Pentadecanoic acid, 14-methyl, methyl ester (1.99\%), 1-Iodo-2methylundecane(1.32\%) found as major compounds. If the potential medicinal value can be established with sound scientific data, it will be a great effort to control \& use this weed that may enhance the financial conditions of the rural farmers.

\section{RECOMMENDATION}

- Individual compound isolation is advisable

- Geographical variation (especially altitude variation) study is advisable as it is a weed found all over Nepal.

- Seasonal variation study is important to understand the medicinal value of this plant

- Further researches are suggested to use this plant as source of iodine as it contains the ethyl iodide compound.

- Biological activities study in animal model is suggested.

\section{REFERENCES}

1. Bairwa RK, R Jee Sharma, Ram Kumar Ray, An updated review on Bidens pilosa L. Der Pharma Chemica, 2010; 2(3): p 325-337.

2. Al. Pe, A Comprehensive Review on Bidens pilosa L.Pharmacologyonline 2008:11(2); p. 185-196.

3. Joshi, A. R., \& Joshi, K. (2000). Indigenous knowledge and uses of medicinal plants by local communities of the Kali Gandaki Watershed Area, Nepal.Journal of Ethnopharmacology, 73(1), 175-183.

4. Christensen L.P., Jopaba K.B., Bioactive polyacetylenes in food plants of the Apieaceae family: Occurance, bioactivity and analysis. Journal of Pharmaceutical and Biomedical Analysis. 2006;41; p. 228-235. 


\section{Original Article}

5. Shrestha, I., \& Joshi, N. (1993). Medicinal plants of the Lele village of Lalitpur district, Nepal. Pharmaceutical Biology, 31(2), 130-134.

6. Matsumoto T., Katsuo K. and Yoshiyuki S., Effects of Bidens pilosa L. var. radiata Scherff, Treated with enzymes on histamine-induced contraction of guinea pig ileum and on histamine release from mast cells. J Smooth Muscle Res, 2009; 45 (2\&3):p. 75-86.

7. Jianguo W.Z., Jun Y., Yanbin W., Peng W., Jinzhong W., Investigation of the extracts from Bidens pilosa Linn. var. radiata Sch. Bip. for antioxidant activities and cytotoxicity against human tumor cells. The Japanese Society of Pharmacognosy and Springer, 2012: 9(14):p 523-531.

8. Khemraj Bairwa, Rajeev Kumar, Ram Jee Sharma, Ram Kumar Roy - An updated review on Bidens Pilosa L. Der Pharma Chemica, 2010, 2(3): 325-337.

9. Ashafa, A. and Afolayan A., Screening the root extracts from Biden pilosa L. var. radiata (Asteraceae) for antimicrobial potentials. Journal of Medicinal Plants Research,2009. 3(8): p. 568-572.

10. Bartolome P.K., Irene M.V and Yang W.C., Bidens pilosa L. (Asteraceae): Botanical properties, Traditional Uses, Phytochemistry and Pharmacology.Evidensed Based Complementary and Alternative Medicine, 2013;

11. Singh G., Prassai A.K., Singh P., Leo V. V., Subbrayan S., Kumar B., Singh B.P., Lalhlenmawia H. and Kumar N.S. Pharmacological potential of Bidens pilosa L. and determination of bioactive compounds using UHPLC-QqQLIT-MS/MS and GC/MS; BMC Complementary and Alternative Medicine, 2017; 17:492.

12. Azeem AK, Dilip C., Prasantha SS, Junise V, Hanan Shahima. Anti-inflammatory activity of the glandular extracts of Thunnus alalunga.Asian Pac J For Med.,2010;3(10): p. 412420.

\section{ANNEXURE}

Annex-1: Procedure of Phytochemical Screening

Detection of alkaloids: Extracts were dissolved individually in dilute Hydrochloric acid and filtered. The filtrates were used to test for the presence of alkaloids.

a) Mayer's Test: Filtrates were treated with the Mayer's reagent (Potassium Mercuric Iodide). Formation of cream precipitate indicates the presence of alkaloids.

b) Dragendroff's Test: Filtrates were treated with Dragendroff's reagent (solution of potassium bismuth iodide). Formation of reddish brown precipitate indicates the presence of alkaloids. 


\section{Original Article}

Detection of carbohydrates: Extracts were dissolved individually in 5ml distilled water and filtered. The filtrates were used to test for the presence of carbohydrates.

Molisch's Test: Filtrates were treated with 2 drops of alcoholic $\alpha$ - naphthol solution in a test tube and $2 \mathrm{ml}$ of Conc. Sulphuric acid was added carefully along the sides of the test tube. Formation of violet ring at the junction indicates the presence of the carbohydrates

Detection of cardiac glycosides: $0.5 \mathrm{mg}$ of each extract diluted with $5 \mathrm{ml}$ water was treated with 2 $\mathrm{ml}$ of glacial acetic acid containing one drop of ferric chloride solution. 1ml of conc. Sulphuric acid was added by the side of the test tube. A brown color ring at the interface indicates the presence of cardiac glycosides.

Detection of saponins: To $0.5 \mathrm{~g}$ of extract was added $5 \mathrm{ml}$ of distilled water in a test tube. The solution was shaken vigorously and observed for a stable persistent froth. The frothing was mixed with 3 drops of olive oil and shaken vigorously after which it was observed for the formation of an emulsion.

Detection of terpenoids: Salkowski's Test: To 0.5 g each of the extract was added $2 \mathrm{ml}$ of $\mathrm{CHCl} 3$ and filtered. The filtrates were treated with few drops of Conc. Sulphuric acid, shaken and allowed to stand. Appearance of golden yellow color indicates the presence of triterpenes.

Detection of flavonoids:

a) Shinoda Test: To a test solution, add few magnesium turnings and conc. hydrochloric acid drop wise, presence of pink scarlet, crimson red or occasionally green to blue color indicates presence of flavonoids. 


\section{Original Article}

b) Alkaline Reagent Test: To the test solution add few drops of sodium hydroxide solution. Intense yellow color is formed which turns colorless on addition of few drops of dilute acid indicates the presence of flavonoids.

c) Zinc Hydrochloride Test: To the test solution add a mixture of zinc dust and conc. hydrochloric acid, gives red color after few minutes indicating presence of flavonoids.

Detection of tannins: $0.5 \mathrm{~g}$ of extract was boiled in $10 \mathrm{ml}$ of water in a test tube and then filtered. A few drops of $0.1 \%$ of ferric chloride was added and observed for brownish green or a blue black coloration.

Detection of proteins and amino acids: To the test solution (2ml), add Biuret reagent $(2 \mathrm{ml})$, violet color indicates the presence of proteins.

Annex - 2:

Table 1: Phytochemical screening of hydro-alcoholic and HEA extracts

\begin{tabular}{|l|l|l|l|l|}
\hline S.N. & Class of compound & Name of the test & $\begin{array}{l}\text { Hydro- } \\
\text { alcoholic } \\
\text { extract }\end{array}$ & HEA extract \\
\hline 1 & Alkaloids & Wagner and Dragendrff's & + & + \\
\hline 2 & Glycosides & Glycoside test & - & - \\
\hline 3 & Saponins & Frothing method & + & - \\
\hline 4 & Tannins & Ferric chloride test & + & + \\
\hline 5 & Flavonoids & $\begin{array}{l}\text { Alkaline reagent test and } \\
\text { Zinc chloride test }\end{array}$ & - & + \\
\hline 6 & Terpenoids & Salkowski's test & + & - \\
\hline 7 & Proteins and amino acids & Biuret test & - & - \\
\hline 8 & Carbohydrates & Molisch's test & - & - \\
\hline & & & $+=$ Present. - = absent \\
\hline
\end{tabular}




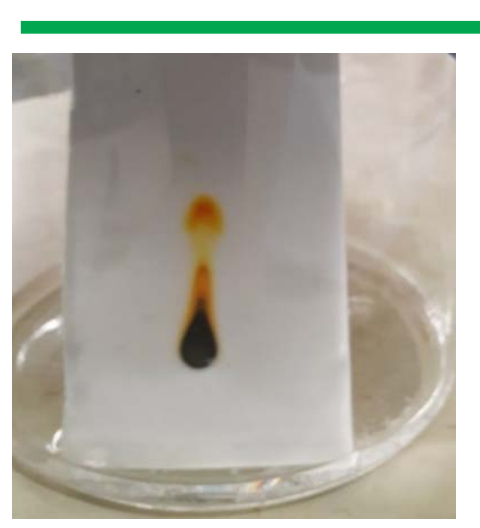

Annex -3: TLC Photographs

Annex- 4: Acute oral toxicity

Table 2: Acute oral toxicity test of hydro-alcoholic and HEA extracts of B. pilosa L.

\begin{tabular}{|l|l|l|l|}
\hline S.N. & Sample Name & LD $_{50}$ value & Remarks \\
\hline 1 & HEA Extract & $>2000 \mathrm{mg} / \mathrm{kg} \mathrm{BW}$ & Tween 20 used as solvent \\
\hline 2 & $\begin{array}{l}\text { Hydro-alcoholic } \\
\text { extract }\end{array}$ & $>2000 \mathrm{mg} / \mathrm{kg} \mathrm{BW}$ & D/W used as solvent \\
\hline
\end{tabular}

\section{Annex-4:}

\begin{tabular}{|l|l|l|l|l|}
\hline S.N. & Treatment & $\begin{array}{l}\text { Concentration } \\
(\mu \mathrm{g} / \mathrm{ml})\end{array}$ & $\begin{array}{l}\text { Absorbance } \\
(560 \mathrm{~nm})\end{array}$ & \% Inhibition \\
\hline 1 & Control & & 0.471 & 0 \\
\hline 2 & $\begin{array}{l}\text { Hydro-alcoholic } \\
\text { extract }\end{array}$ & 500 & 0.310 & 34.18 \\
\hline 3 & $\begin{array}{l}\text { Hydro-alcoholic } \\
\text { extract }\end{array}$ & 1000 & 0.237 & 49.68 \\
\hline 4 & \begin{tabular}{l} 
HEA extract \\
\hline 5
\end{tabular} & 500 & 0.273 & 42.03 \\
\hline 6 & HEA extract & 1000 & 0.210 & 55.41 \\
\hline
\end{tabular}

Table 3: In vitro anti-inflammatory activity by HRBC membrane stabilization 